\title{
The Human Orphan Nuclear Receptor PXR Is Activated by Compounds That Regulate CYP3A4 Gene Expression and Cause Drug Interactions
}

\author{
Jürgen M. Lehmann,, ${ }^{\star}$ David D. McKee, ${ }^{\ddagger}$ Michael A. Watson, ${ }^{\star}$ Timothy M. Willson, ${ }^{\S}$ John T. Moore, ${ }^{\ddagger}$ and Steven A. Kliewer ${ }^{\star}$ \\ $*$ Department of Molecular Endocrinology, ${ }^{\ddagger}$ Department of Molecular Sciences, and ${ }^{\S}$ Department of Medicinal Chemistry, Glaxo \\ Wellcome Research and Development, Research Triangle Park, North Carolina 27709
}

\begin{abstract}
The cytochrome P-450 monooxygenase 3A4 (CYP3A4) is responsible for the oxidative metabolism of a wide variety of xenobiotics including an estimated $60 \%$ of all clinically used drugs. Although expression of the CYP3A4 gene is known to be induced in response to a variety of compounds, the mechanism underlying this induction, which represents a basis for drug interactions in patients, has remained unclear. We report the identification of a human (h) orphan nuclear receptor, termed the pregnane $X$ receptor (PXR), that binds to a response element in the $C Y P 3 A 4$ promoter and is activated by a range of drugs known to induce CYP3A4 expression. Comparison of hPXR with the recently cloned mouse PXR reveals marked differences in their activation by certain drugs, which may account in part for the species-specific effects of compounds on CYP3A gene expression. These findings provide a molecular explanation for the ability of disparate chemicals to induce CYP3A4 levels and, furthermore, provide a basis for developing in vitro assays to aid in predicting whether drugs will interact in humans. (J. Clin. Invest. 1998. 102:1016-1023.) Key words: nuclear receptor - orphan receptor - transcription factor • cytochrome P450 3A • drug interactions
\end{abstract}

\section{Introduction}

Members of the cytochrome P-450 (CYP) ${ }^{1}$ family of hemoproteins are critical in the oxidative metabolism of a wide variety of endogenous substances and xenobiotics, including various carcinogens and toxins (1). In humans, the CYP3A4 monooxy-

Address correspondence to Steven Kliewer, Department of Molecular Endocrinology, Room 3.3124, Glaxo Wellcome Research and Development, Five Moore Drive, Research Triangle Park, NC 27709. Phone: 919-483-5601; FAX: 919-483-6147; E-mail: sak15922@ glaxowellcome.com

Received for publication 13 April 1998 and accepted in revised form 25 June 1998.

1. Abbreviations used in this paper: CARLA, coactivator-receptor ligand interaction assay; CAT, chloramphenicol acetyl transferase; CYP3A, cytochrome P450 3A; DBD, DNA binding domain; DR, direct repeat; ER, everted repeat; EST, expressed sequence tag; GR, glucocorticoid receptor; GST, glutathione S transferase; h, human; LBD, ligand binding domain; $\mathrm{m}$, mouse; PCN, pregnenolone $16 \alpha$-carbonitrile; PXR, pregnane $\mathrm{X}$ receptor; PXRE, PXR response element; $\mathrm{RXR}$, retinoid $\mathrm{X}$ receptor; tk, thymidine kinase promoter.

J. Clin. Invest.

(C) The American Society for Clinical Investigation, Inc. 0021-9738/98/09/1016/08 \$2.00

Volume 102, Number 5, September 1998, 1016-1023

http://www.jci.org genase plays a major role in the biotransformation of drugs due to its abundance in liver and intestine and its broad substrate specificity. CYP3A4 catalyzes the metabolism of $>60 \%$ of all drugs that are in use including contraceptive steroids, immunosuppressive agents, imidazole antimycotics, and macrolide antibiotics (2).

Expression of the CYP3A4 gene is markedly induced both in vivo and in primary hepatocytes in response to treatment with a variety of compounds. Many of the most efficacious inducers of $C Y P 3 A 4$ expression are commonly used drugs such as the glucocorticoid dexamethasone, the antibiotic rifampicin, and the antimycotic clotrimazole $(2,3)$. The inducibility of CYP3A4 expression levels coupled with the broad substrate specificity of the CYP3A4 protein represent a basis for drug interactions in patients undergoing combination drug therapy. While attempts have been made to develop in vitro assays with which to profile efficiently the effects of new compounds on CYP3A expression levels, these efforts have been hampered by species-specific effects that have limited the utility of using animals tissues and cells for testing purposes. Thus, analysis of the effects of compounds on $C Y P 3 A 4$ gene expression has been largely restricted to laborious assays involving human liver tissue.

Recently, several laboratories have investigated the molecular basis for the induction of $C Y P 3 A 4$ gene expression. The $C Y P 3 A 4$ promoter has been cloned, and a 20-bp region residing $\sim 150$ bp upstream of the transcription initiation site has been shown to confer responsiveness to dexamethasone and rifampicin $(4,5)$. This region contains two copies of the $\mathrm{AG}(\mathrm{G} /$ T)TCA motif recognized by members of the nuclear receptor superfamily, suggesting that a nuclear receptor might be responsible for mediating at least some of the effects of the chemical inducers of $C Y P 3 A 4$ expression. However, the proteins that bind to this response element have not yet been characterized.

In this report, we identify a nuclear receptor, termed hPXR, that binds to the rifampicin/dexamethasone response element in the $C Y P 3 A 4$ promoter as a heterodimer with the 9-cis retinoic acid receptor RXR. hPXR is related to the mouse (m) PXR1, which we recently cloned and showed to be activated by dexamethasone, pregnenolone $16 \alpha$-carbonitrile (PCN), and other compounds known to induce expression of the $C Y P 3 A 1$ gene, the predominant form of $C Y P 3 A$ in rat liver and intestine $(4,5)$. The hPXR/RXR complex is activated by dexamethasone, rifampicin, and a variety of other, structurally diverse compounds previously shown to modulate CYP3A4 expression. We provide several lines of evidence indicating that hPXR serves as a key transcriptional regulator of the $C Y P 3 A 4$ gene.

\section{Methods}

Chemicals. Dexamethasone-t-butylacetate and RU486 were purchased from Research Plus, Inc. (Bayonne, NJ) and Biomol (Ply- 
mouth Meeting, PA), respectively. All other compounds were purchased from either Sigma Chemical Co. (St. Louis, MO) or Steraloids, Inc. (Wilton, NH).

Molecular cloning of $h P X R c D N A s$. An expressed sequence tag (EST) was identified in the Incyte LifeSeq ${ }^{\circledR}$ proprietary database (clone identification number 2211526) that contained nucleotides 444-2111 of the $h P X R$ sequence. An oligonucleotide derived from this EST sequence (5'-CTGCTGCGCATCCAGGACAT-3') was used to screen a pCMV-SPORT human liver cDNA library (GIBCO BRL, Gaithersburg, MD) using Gene Trapper solution hybridization cloning technology (GIBCO BRL). Two clones were obtained that encoded full-length hPXR, one containing nucleotides 1-2146, the other containing nucleotides $102-2118$. The sequence of the longer clone is shown in Fig. $1 A$. Sequences were aligned and analyzed by the University of Wisconsin Genetics Computer Group programs.

Plasmids. The expression vector pSG5-hPXR was generated by PCR amplification and subcloning of nucleotides 1-1608 of the hPXR clone into the pSG5 expression vector (Stratagene, La Jolla, CA). pSG5-hPXR $\triangle$ ATG was generated by PCR amplification of cDNA encoding amino acids 1-434 of hPXR using oligonucleotides 5'-GGGTGTGGGGAATTCACCACCATGGAGGTGAGACCCAAAGAAAGC-3' (sense) and 5'-GGGTGTGGGGGATCCTCAGCTACCTGTGATGCCG-3' (antisense) and insertion into Eco RI/Bam HIcut pSG5. The bacterial expression vector pGEX-hPXR was generated by PCR amplification of cDNA encoding amino acids 108-434 and insertion into pGEX-2T (Pharmacia, Piscataway, NJ). The re-

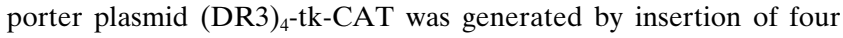
copies of a double-stranded oligonucleotide containing the CYP3A1 DR3 PXRE (5'-GATCAGACAGTTCATGAAGTTCATCTAGATC-3') into the Bam HI site of pBLCAT2 (6). The reporter plasmid (ER6) ${ }_{3}$-tk-CAT was generated by insertion of three copies of the CYP3A4 ER6 PXRE (5'-GATCAATATGAACTCAAAGGAGGTCAGTG-3') into the Bam HI site of pBL2CAT. The pRSETSRC1.14 expression plasmid has been previously described (7). All constructs were confirmed by sequence analysis.

Cotransfection assays. CV-1 cells were plated in 24-well plates in DME medium supplemented with $10 \%$ charcoal-stripped fetal calf serum at a density of $1.2 \times 10^{5}$ cells per well. In general, transfection mixes contained $33 \mathrm{ng}$ of receptor expression vector, $100 \mathrm{ng}$ of reporter plasmid, $200 \mathrm{ng}$ of $\beta$-galactosidase expression vector ( $\mathrm{pCH} 110$; Pharmacia), and $166 \mathrm{ng}$ of carrier plasmid. Cells were transfected overnight by lipofection using Lipofectamine (GIBCO BRL) according to the manufacturer's instructions. The medium was changed to DME medium supplemented with $10 \%$ delipidated calf serum (Sigma) and cells were incubated for an additional $24 \mathrm{~h}$. Cell extracts were prepared and assayed for CAT and $\beta$-galactosidase activities as previously described (8).

Northern analysis. An $\sim 1.0-\mathrm{kb}$ fragment encoding the ligand binding domain (LBD) of hPXR was $\left[{ }^{32} \mathrm{P}\right]$-labeled by random priming and used to probe human multiple tissue Northern blots (Clontech, Palo Alto, CA). Blots were hybridized in ExpressHyb solution (Clontech) at $42^{\circ} \mathrm{C}$ overnight. Final washes were performed with $0.1 \times$ SSC, $0.1 \%$ SDS at $58^{\circ} \mathrm{C}$.

Band shift assays. hPXR, mPXR1, and hRXR $\alpha$ were synthesized in vitro using the TNT rabbit reticulocyte lysate coupled in vitro transcription/translation system (Promega, Madison, WI) according to the manufacturer's instructions. Gel mobility shift assays $(20 \mu \mathrm{l})$ contained $10 \mathrm{mM}$ Tris (pH 8.0), $40 \mathrm{mM} \mathrm{KCl}, 0.05 \% \mathrm{NP}-40,6 \%$ glycerol, $1 \mathrm{mM}$ DTT, $0.2 \mu \mathrm{g}$ of poly(dI-dC), and $2.5 \mu \mathrm{l}$ each of in vitro synthesized PXR and RXR proteins. Competitor oligonucleotides were included at a 10- or 50-fold excess as indicated in the figure legends. After a 10-min incubation on ice, $10 \mathrm{ng}$ of $\left[{ }^{32} \mathrm{P}\right]$-labeled oligonucleotide was added, and the incubation continued for an additional $10 \mathrm{~min}$. DNA-protein complexes were resolved on a $4 \%$ polyacrylamide gel in $0.5 \times$ TBE $(1 \times$ TBE $=90 \mathrm{mM}$ Tris, $90 \mathrm{mM}$ boric acid, $2 \mathrm{mM}$ EDTA). Gels were dried and subjected to autoradiography at $-70^{\circ} \mathrm{C}$. The following oligonucleotides were used as either radiolabeled probes or competitors (sense strand is shown): $C Y P 3 A 4$ ER6: 5'-GAT-
CAATATGAACTCAAAGGAGGTCAGTG-3'; CYP3A4 ER6m1: 5'-GATCAATATGTTCTCAAAGGAGAACAGTG-3'; CYP3A4 ER6m2: 5'-GATCAATAACAACTCAAAGGAGGTCAGTG-3'; CYP3A1 DR3: 5'-GATGCAGACAGTTCATGAAGTTCATCTAGATC-3'.

CARLA. GST-hPXR fusion protein was expressed in BL21(DE3)plysS cells and bacterial extracts prepared by one cycle of freeze-thaw of the cells in protein lysis buffer containing $10 \mathrm{mM}$ Tris, $\mathrm{pH}$ 8.0, $50 \mathrm{mM} \mathrm{KCl}, 10 \mathrm{mM}$ DTT, and 1\% NP-40 followed by centrifugation at $40,000 \times g$ for $30 \mathrm{~min}$. Glycerol was added to the resulting supernatant to a final concentration of $10 \%$. Lysates were stored at $-80^{\circ} \mathrm{C}$. $\left.{ }^{35} \mathrm{~S}\right] \mathrm{SRC} 1.14$ was generated using the TNT rabbit reticulocyte system (Promega) in the presence of Pro-Mix (Amersham, Arlington Heights, IL). Coprecipitation reactions included $25 \mu \mathrm{l}$ of lysate containing GST-hPXR fusion protein, $25 \mu \mathrm{l}$ incubation buffer $(50 \mathrm{mM} \mathrm{KCl}, 40 \mathrm{mM}$ HEPES pH 7.5, $5 \mathrm{mM} \beta$-mercaptoethanol, $0.1 \%$ Tween-20, $1 \%$ nonfat dry milk), $5 \mu \mathrm{l}\left[{ }^{35}\right.$ S]SRC1.14, and vehicle $(1 \%$ DMSO) or compounds as indicated in the figure legends. The mixtures were incubated for $25 \mathrm{~min}$ at $4^{\circ} \mathrm{C}$ with gentle mixing before the addition of $15 \mu \mathrm{l}$ of glutathione-sepharose 4B beads (Pharmacia) that had been extensively washed with protein lysis buffer. Reactions were incubated with gentle mixing at $4^{\circ} \mathrm{C}$ for an additional $25 \mathrm{~min}$. The beads were pelleted at $3,000 \mathrm{rpm}$ in a microfuge and washed three times with protein incubation buffer containing either vehicle alone, dexamethasone-t-butylacetate, rifampicin, or clotrimazole. After the last wash, the beads were resuspended in $25 \mu \mathrm{l}$ of $2 \times$ SDSPAGE sample buffer containing $50 \mathrm{mM}$ DTT. Samples were heated at $100^{\circ} \mathrm{C}$ for $5 \mathrm{~min}$ and loaded onto a $10 \%$ Bis-Tris PAGE gel. Gels were dried and subjected to autoradiography.

\section{Results}

Molecular cloning and tissue expression pattern of $h P X R$. A human EST was identified in the Incyte database that was highly homologous to a portion of the $m P X R 1 \mathrm{cDNA}$ (7). Two larger clones were isolated in a screen of a human liver cDNA library using an oligonucleotide within the EST as a probe. The longest of these clones was 2,146 bp in length (Fig. $1 A$ ) and encoded a new member of the nuclear receptor superfamily that was $96 \%$ and $76 \%$ identical to mPXR 1 in the DNA binding domain (DBD) and LBD, respectively (Fig. $1 B$ ). In terms of other members of the nuclear receptor superfamily, hPXR was most closely related to the Xenopus laevis orphan receptor ONR1 (9) and the vitamin D receptor (Fig. $1 B$ ). Notably, the $h P X R$ sequence lacked an AUG initiator codon in between an in-frame stop codon (nucleotides 205-207 in the $h P X R$ sequence) and the start of the region encoding the DBD. However, transfection experiments performed in CV-1 cells with the $h P X R$ clone and a reporter plasmid containing four copies of an established mPXR binding site from the rat $C Y P 3 A 1$ gene promoter inserted upstream of the minimal thymidine kinase (tk) promoter and the chloramphenicol acetyltransferase (CAT) gene (7) demonstrated that the $h P X R$ clone encoded a functional nuclear receptor that was activated efficiently by dexamethasone-t-butylacetate, a known mPXR1 ligand (7; Fig. $1 C$ ).

Examination of the $h P X R$ sequence revealed an in-frame CUG codon (nucleotides 304-306) surrounded by a favorable Kozak sequence (10). There is precedent for the use of CUG codons to initiate translation of eukaryotic proteins, including the nuclear receptor RARß4 $(10,11)$. Initiation of translation at this CUG codon would yield a protein of 434 amino acids, three longer than $\mathrm{mPXR} 1$, with a predicted MW of $50 \mathrm{kD}$. To determine whether translation of the $h P X R$ cDNA initiated at 
A

1 TGAAATATAGGTGAGAGACAAGATTGTCTCATATCCGGGGAATCATAACCTATGACTAG 61 GACGGGAAGAGGAAGCACTGCCTTTACTTCAGTGGGAATCTCGGCCTCAGCCTGCAAGCC 121 AAGTGTTCACAGTGAGAAAAGCAAGAGAATAAGCTAATACTCCTGTCCTGAACAAGGCAG 181 CGGCTCCTTGGTAAAGCTACTCCITGATCGATCCTTTGCACCGGATTGTTCAAAGTGGAC 241 CCCAGGGGAGAAGTCGGAGCAAAGAACTTACCACCAAGCAGTCCAAGAGGCCCAGAAGCA 301 AACCTGGAGGTGAGACCCAAAGAAAGCTGGAACCATGCTGACTITGTACACTGTGAGGAC $\begin{array}{llllllllllllllllllll}L & E & V & R & P & K & E & S & W & N & H & A & D & F & V & H & C & E & D & 19\end{array}$ 361 ACAGAGTCTGTTCCTGGAAAGCCCAGTGTCAACGCAGATGAGGAAGTCGGAGGTCCCCAA $\begin{array}{lllllllllllllllllllll}T & E & S & V & P & G & K & P & S & V & N & A & D & E & E & V & G & G & P & Q & 39\end{array}$ 421 ATCTGCCGTGTATGTGGGGACAAGGCCACTGGCTATCACTTCAATGTCATGACATGTGAA

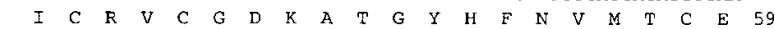
81 GGATGCAAGGGCTTTTTCAGGAGGGCCATGAAACGCAACGCCCGGCTGAGGTGCCCCTTC $\begin{array}{llllllllllllllllllllll}G & C & K & G & F & F & R & R & A & M & K & R & N & A & R & L & R & C & P & F & 79\end{array}$ 1 CGGAAGGGCCCTGCGAGATCACCCGGAAGACCCGGCGACAGTGCCAGGCCTGCCGCCTG $\begin{array}{lllllllllllllllllllllll}R & K & G & A & C & E & I & T & R & K & T & R & R & Q & C & Q & A & C & R & L & 99\end{array}$ 1 CGCAAGTGCCTGGAGAGCGGCATGAAGAAGGAGATGATCATGTCCGACGAGGCCGTGGAG $\begin{array}{lllllllllllllllllllll}R & K & C & L & E & S & G & M & K & K & E & M & I & M & S & D & E & A & V & E & 119\end{array}$ GAGAGGCGGGCCTTGATCAAGCGGAAGAAAAGTGAACGGACAGGGACTCAGCCACTGGGA $\begin{array}{llllllllllllllllllllll}\text { E } & R & R & A & \text { L } & I & K & R & K & K & \text { S } & \text { E } & R & \text { T } & \text { G } & \text { T } & Q & \text { P } & \text { L } & \text { G } & 139\end{array}$ GTGCAGGGGCIGACAGAGGAGCAGCGGATGATGATCAGGGAGCTGATGGACGCTCAGATG $\begin{array}{lllllllllllllllllllll}V & Q & G & L & T & E & E & Q & R & M & M & I & R & E & L & M & D & A & Q & M & 159\end{array}$ AAAACCTTTGACACTACCTPCTCCCATTTCAAGAATTTCCGGCTGCCAGGGGTGCTTAGC $\begin{array}{lllllllllllllllllllllll}K & T & F & D & T & T & F & S & H & F & K & N & F & R & L & P & G & V & L & S & 179\end{array}$ 41 AGTGGCTGCGAGTTGCCAGAGTCTCTGCAGGCCCCATCGAGGGAAGAAGCTGCCAAGTGG $\begin{array}{lllllllllllllllllllll}S & G & C & E & \text { L } & \text { P } & \text { E } & \text { S } & \text { L } & Q & \text { A } & \text { P } & \text { S } & \text { R } & \text { E } & \text { E } & \text { A } & \text { A } & \text { K } & \text { W } & 199\end{array}$ AGCCAGGTCCGGAAAGATCTGTGCTCTTTGAAGGTCTCTCTGCAGCTGCGGGGGGAGGAT $\begin{array}{lllllllllllllllllllll}S & Q & \text { V } & R & K & D & \text { L } & C & \text { S } & \text { L } & K & V & S & \text { L } & Q & \text { L } & \text { R } & G & \text { E } & D & 219\end{array}$

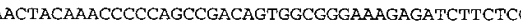
$\begin{array}{llllllllllllllllllllll}G & S & V & W & N & Y & K & P & P & A & D & S & G & G & K & E & I & F & S & L & 239\end{array}$ 1021 CTGCCCCACATGGCTGACATGTCAACCTACATGTTCAAAGGCATCATCAGCTTTGCCAAA. $\begin{array}{llllllllllllllllllllll}\text { I } & P & \text { H } & \text { M } & \text { A } & D & M & S & \text { T } & \text { Y } & \text { M } & \text { F } & \text { K } & \text { G } & \text { I } & \text { I } & \text { S } & \text { F } & \text { A } & \text { K } & 259\end{array}$ 1081 GTCATCTCCIACTTCAGCGACTIGCCCATCGAGGACCAGATCTCCCTGCTGAAGGGGCC $\begin{array}{llllllllllllllllllllll}V & I & S & Y & F & R & D & L & P & I & E & D & Q & I & S & I & I & K & G & A & 279\end{array}$ $\begin{array}{lllllllllllllllllllll}A & F & E & L & C & Q & L & R & F & N & T & V & F & N & A & E & T & G & T & W & 299\end{array}$ 1 GAGTGTGGCCGGCTGTCCTACTGCTTGGAAGACACTGCAGGTGGCTTCCAGCAACTTCTA $\begin{array}{lllllllllllllllllllll}E & C & G & R & \text { L } & S & Y & C & L & E & D & T & A & G & G & F & Q & Q & L & L & 319\end{array}$ 1261 CTGGAGCCCATGCTGAAATTCCACTACATGCTGAAGAAGCTGCAGCTGCATGAGGAGGAG $\begin{array}{lllllllllllllllllllll}L & E & P & M & L & K & F & H & Y & M & L & K & K & L & Q & L & H & E & E & E & 339\end{array}$ 1321 TATGTGCTGATGCAGGCCATCTCCCTCTTCTCCCCAGACCGCCCAGGTGTGCTGCAGCAC $\begin{array}{lllllllllllllllllllll}Y & V & L & M & Q & A & I & S & L & F & S & F & D & R & P & G & V & L & Q & H & 35\end{array}$ 381 CGCGTGGTGGACCAGCTGCAGGAGCAATTCGCCATTACTCTGAAGTCCTACATTGAATGC $\begin{array}{llllllllllllllllllllll}R & V & V & D & Q & L & Q & E & Q & F & A & I & T & L & K & S & Y & I & E & C & 379\end{array}$ 1441 AATCGGCCCCAGCCTGCTCATAGGTTCTTGTTCCTGAAGATCATGGCTATGCTCACCGAG $\begin{array}{lllllllllllllllllllllll}N & R & P & Q & P & A & H & R & F & L & F & L & K & I & M & A & M & L & T & E & 399\end{array}$ 1501 CTCCGCAGCATCAATGCTCAGCACACCCAGCGGCTGCTGCGCATCCAGGACATACACCCC $\begin{array}{lllllllllllllllllllll}I & R & S & I & N & A & Q & H & T & Q & R & L & L & R & I & Q & D & I & H & P & 419\end{array}$ 1561 T"TTGCTACGCCCCTCATGCAGGAGTTGTTCGGCATCACAGGTAGCTGAGCGGCTGCCCI"I $\begin{array}{lllllllllllllllllll}F & A & T & P & L & M & Q & E & L & F & G & I & T & G & S\end{array}$

1621 GGGTGACACCTCCGAGAGGCAGCCAGACCCAGAGCCCTCTGAGCCGCCACTCCCGGGCCA 1681 AGACAGATGGACACTCCCAACACCCGACAATCCCCTCCPCCCCTCTCTCCCD 1741 CCTGCTAT 1741 cCHGCTAGAC 1801 TCAGTCTGTAGGGAGGAGCCACAGACTCTTACGTGGAGAGTGCACTGACCTGTAGGTC 1861 AGGACCATCAGAGAGGCAAGGTTGCCCTTTCCTTTTAAAAGGCCCTGTGGTCTGGGGAGA. 1921 AATCCCTCAGATCCCACTAAAGTGTCAAGGTGTGGAAGGGACCAAGCGACCAAGGATAGG 1981 CCATCTGGGGTCTATGCCCACATACCCACGTTTGTTCGCTTCCTGAGTCTTTTCATTGCT 2041 ACCTCTAATAGTCCTGTCTCCCACTTCCCACTCGTTCCCCTCCTCTTCCGAGCTGCTTTG 2101 TGGGCTCCAGGCCTGTACTCATCGGCAGGTGCATGAGTATCTGTGG
B

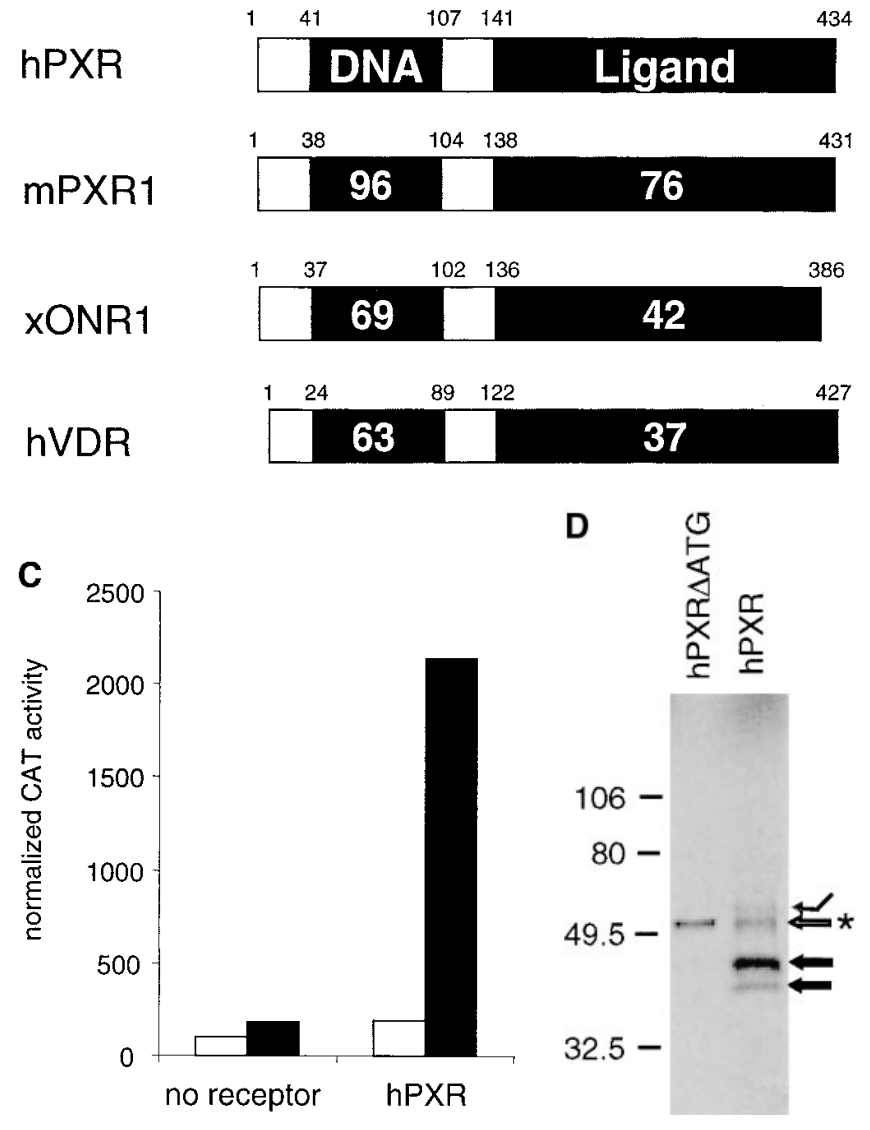

Figure 1. Molecular cloning of hPXR. The GenBank accession number for hPXR is AF061056. $(A)$ Nucleotide and predicted amino acid sequences of hPXR. (B) Amino acid sequence comparison between hPXR, mPXR1, Xenopus orphan nuclear receptor 1 (xONR1), and the human vitamin D receptor (hVDR). Numbers indicate percent amino acid identity in the DBDs and LBDs. $(C)$ The hPXR clone encodes a functional nuclear receptor. Transfection assays were performed with a pSG5-hPXR expression vector containing the wild-type 5' region of the hPXR cDNA and a reporter plasmid containing four copies of the

CYP3A1 DR3 PXRE. Cells were treated with vehicle alone (0.1\% DMSO) or $10 \mu \mathrm{M}$ of dexamethasone-t-butylacetate. Cell extracts were subsequently assayed for CAT activity. Data points represent the mean of assays performed in duplicate. $(D)$ Translation of the full-length hPXR initiates at a non-AUG codon. In vitro transcription and translation were performed with the pSG5-hPXR expression vector containing the wildtype 5 ' region of the hPXR cDNA or pSG5-hPXR $\triangle \mathrm{AUG}$, in which the CUG codon at nucleotide positions 304-306 was modified to AUG. The $50-\mathrm{kD}$ product synthesized when either template was used is indicated by an open arrow and an asterisk. Two shorter products that are likely to represent translation initiation at methionine-56 and methionine-69 within the DBD are indicated by closed arrows. A longer translation product present at low levels is indicated by the bent arrow. Size markers (in kilodaltons) are indicated at left.

the CUG codon, $h P X R$ RNA containing the wild-type 5' region was translated in the presence of $\left.{ }^{35} S\right]$ methionine using rabbit reticulocyte lysates. As a control, $h P X R$ RNA, in which this CUG codon had been mutated to the optimal AUG (hPXR $\Delta$ AUG), was also translated in vitro. Translation of the wild-type $h P X R$ RNA resulted in an $\sim 50-\mathrm{kD}$ protein that comigrated with the translation product of hPXR $\Delta$ AUG RNA (Fig. $1 \mathrm{D}$, open arrow with asterisk). This $50-\mathrm{kD}$ product was not produced when $h P X R$ antisense RNA was used in the translation reaction (data not shown). Much lower amounts of an $\sim 53-\mathrm{kD}$ translation product were also produced in translation reactions performed with $h P X R$ RNA (Fig. $1 D$, bent arrow), indicating that a small amount of translation initiated at other non-AUG codons upstream of the CUG codon. How- ever, our results indicate that the CUG codon represents the principal translation initiation site for $\mathrm{hPXR}$ containing a functional DBD.

We next examined the tissue expression pattern of $h P X R$ via Northern analysis using blots containing poly(A) ${ }^{+}$RNA prepared from multiple adult tissues. $h P X R$ mRNA was expressed most abundantly in liver and was also present in the colon and small intestine (Fig. 2). Three transcripts of different size were detected in each of these tissues: a prominent $2.6-\mathrm{kb}$ product and two less abundant messages of $\sim 4.3$ and $5 \mathrm{~kb}$. We recently showed that the $m P X R$ gene is also abundantly expressed in liver and small intestine (7). Whereas $M P X R$ message was also detected at low levels in stomach and kidney, we did not detect mRNA for $h P X R$ in these tissues (Fig. 2 and 


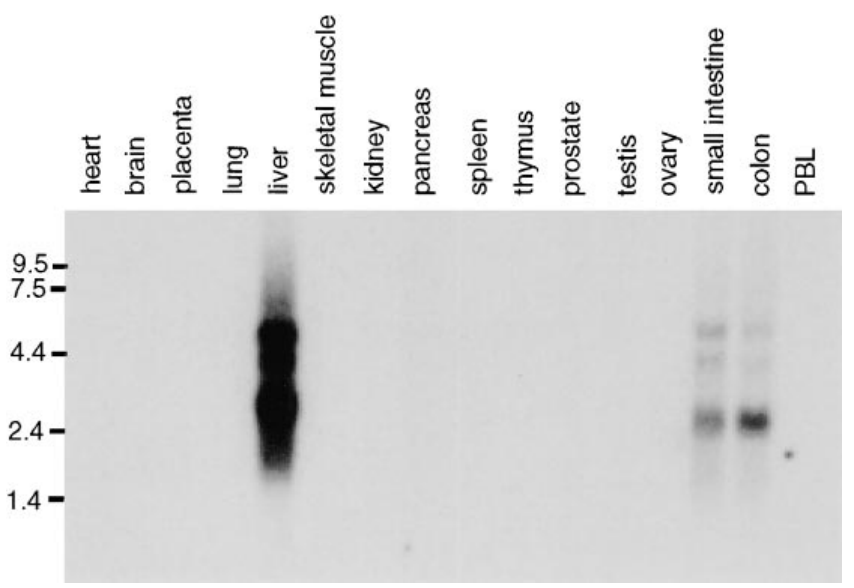

Figure 2. Northern blot analysis of hPXR expression pattern in adult tissues. RNA size markers (in kilobases) are indicated at left.

data not shown). Thus, both $h P X R$ and $m P X R$ are most abundantly expressed in the liver and tissues of the gastrointestinal tract; however, there are differences in $P X R$ expression patterns in mice and humans.

hPXR activates transcription through a response element in the CYP3A4 gene promoter. We recently provided several lines of evidence that mPXR1 regulates $C Y P 3 A 1$ gene expression: mPXR1 was activated by compounds known to activate
CYP3A1 gene expression including glucocorticoids and antiglucocorticoids; mPXR1 and $C Y P 3 A 1$ gene expression colocalized in the liver and small intestine; and mPXR1 bound to a response element in the $C Y P 3 A 1$ gene promoter that had been determined previously to confer responsiveness to glucocorticoids and antiglucocorticoids $(7,12,13)$. The findings that the $C Y P 3 A 4$ gene is also expressed in the liver and intestine and that this expression is induced in response to glucocorticoids and antiglucocorticoids $(14,15)$ led us to investigate whether hPXR regulates $C Y P 3 A 4$ gene expression.

The induction of $C Y P 3 A 4$ expression in response to dexamethasone and rifampicin has been localized to an $\sim 20$-bp region of the promoter that contains two copies of the nuclear receptor half-site sequence $\mathrm{AG}(\mathrm{G} / \mathrm{T}) \mathrm{TCA}$ organized as an everted repeat (ER) and separated by $6 \mathrm{bp}$, an ER6 motif (5; Fig. $3 \mathrm{~B}$ ). This ER6 motif is highly conserved in the promoters of $C Y P 3 A$ gene family members of several species (5). Interestingly, this half-site configuration is very different from that found in the CYP3A1 PXR response element (PXRE), which is composed of two half-sites organized as a direct repeat (DR) with a three nucleotide spacer, a DR3 motif (7). To determine whether hPXR could regulate transcription through the ER6 motif, a reporter plasmid was generated containing three copies of the $C Y P 3 A 4$ ER6 response element upstream of the tk promoter and CAT gene. Cotransfection assays were performed with the (ER6) 3 -tk-CAT reporter and pSG5-hPXR$\Delta$ ATG expression plasmids in CV-1 cells that were either treated with vehicle alone or $10 \mu \mathrm{M}$ dexamethasone-t-butylac-

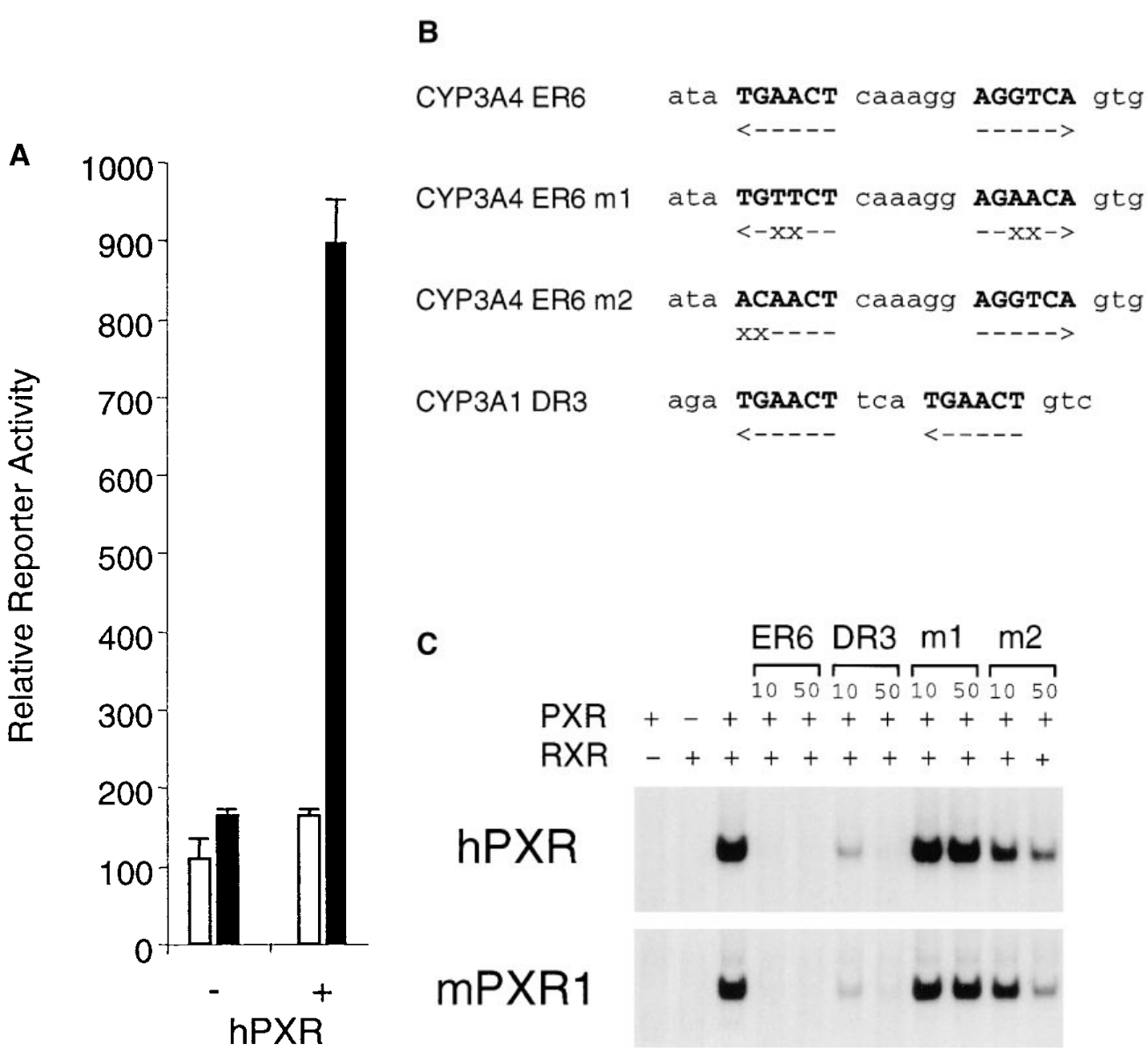

Figure 3. hPXR activates transcription through an ER6 element in the $C Y P 3 A 4$ promoter. (A) $\mathrm{CV}$-1 cells were cotransfected with the (ER6) ${ }_{3}$-tk-CAT reporter plasmid in either the absence $(-)$ or presence $(+)$ of the pSG5-hPXR $\Delta$ ATG expression plasmid and treated with vehicle alone (open bars) or 10 $\mu \mathrm{M}$ dexamethasone-t-butylacetate (closed bars). Cell extracts were subsequently assayed for CAT activity. Data represent the mean of assays performed in triplicate \pm SE. (B) Oligonucleotides used in band shift assays. The positions of nuclear receptor half-site motifs and mutations are indicated. $(C)$ Band shift assays were performed with a radiolabeled oligonucleotide containing the $C Y P 3 A 4$ ER6 PXRE and hRXR $\alpha$ and either hPXR (top) or mPXR1 (bottom). Unlabeled competitor oligonucleotides were added at a 10 -fold or 50-fold molar excess as indicated. 
etate. hPXR induced reporter levels in the presence of dexamethasone-t-butylacetate (Fig. $3 A$ ), demonstrating that hPXR can activate transcription through the $C Y P 3 A 4$ ER6 motif.

To determine whether hPXR interacted directly with the CYP3A4 ER6 response element, band shift assays were performed. Since mPXR1 binds to DNA as a heterodimer with RXR (7), we suspected that hPXR would require RXR for high-affinity interactions with DNA. Neither hPXR nor RXR bound to a radiolabeled oligonucleotide containing the $C Y P 3 A 4$ ER6 motif on their own (Fig. $3 C$ ). However, hPXR and RXR bound efficiently as a heterodimer to the ER6 PXRE. The hPXR/RXR complex was competed efficiently by unlabeled oligonucleotides encoding either the ER6 PXRE from the $C Y P 3 A 4$ promoter or the DR3 PXRE from the $C Y P 3 A 1$ promoter that we previously defined as a mPXR1/RXR binding site (7; Fig. $3 C$ ). Thus, the hPXR/RXR heterodimer interacted efficiently with two response elements with remarkably different architecture. Little or no competition was seen when competitor oligonucleotides were used that contained mutations in either the $5^{\prime}$ half-site or both half-site sequences of the ER6 PXRE (Fig. $3 C$ ). The same binding profile was observed when the mPXR1 was substituted for hPXR (Fig. $3 C$ ). We conclude from these experiments that hPXR binds efficiently to the CYP3A4 ER6 PXRE as a heterodimer with RXR and that $\mathrm{hPXR}$ and $\mathrm{mPXR} 1$ have very similar DNA binding profiles.

Differential activation of human and $m P X R$. CYP3A4 gene expression is induced in response to a remarkable array of xenobiotics including synthetic steroids (15-18), macrolide antibiotics (19), antimycotics (20), HMG-CoA reductase inhibitors (statins) $(21,22)$, and phenobarbital and related compounds (17). We next sought to determine whether hPXR might mediate the effects of some or all of these compounds on $C Y P 3 A 4$ expression. CV-1 cells were cotransfected with the pSG5hPXR $\Delta$ ATG expression plasmid and the (ER6) ${ }_{3}$-tk-CAT reporter plasmid, and the cells were treated with micromolar concentrations of a number of compounds that are known to induce $C Y P 3 A$ gene expression in humans and/or rodents. As shown in Fig. $4 A$, hPXR was activated by the synthetic steroids dexamethasone, dexamethasone-t-butylacetate, $\mathrm{PCN}$, RU486, spironolactone, and cyproterone-acetate. Dexamethasone-t-butylacetate and RU486 were the most efficacious activators of hPXR among the synthetic steroids tested. Notably, the antibiotic rifampicin and the antimycotic clotrimazole were both efficacious activators of hPXR (Fig. $4 A$ ). The antihypercholesterolemic drug lovastatin also activated hPXR as did phenobarbital and the organochlorine pesticide transnonachlor (Fig. $4 A$ ). Thus, hPXR is activated by a remarkably diverse group of synthetic compounds that are known to induce CYP3A4 gene expression (Fig. $4 C$ ).

Complete dose response analysis was performed on several of the synthetic hPXR activators including dexamethasone, RU486, rifampicin, clotrimazole, and lovastatin. Rifampicin was the most potent of these compounds, activating hPXR with a half-maximal effective concentration $\left(\mathrm{EC}_{50}\right)$ of $\sim 800$ $\mathrm{nM}$ (Fig. $4 \mathrm{~B}$ ). This $\mathrm{EC}_{50}$ value is in good agreement with that for rifampicin-mediated induction of CYP3A4 activity in human primary hepatocytes (E. LeCluyse, personal communication). We note that in patients treated with the standard 600$\mathrm{mg}$ oral dose of rifampicin, peak blood levels average $10 \mu \mathrm{M}$ and can reach levels as high as $40 \mu \mathrm{M}$, well above the concentration required to activate hPXR (23). Lovastatin and clotri- mazole activated hPXR with $\mathrm{EC}_{50}$ values of roughly $1-5 \mu \mathrm{M}$, and dexamethasone and RU486 activated hPXR with $\mathrm{EC}_{50}$ values of $\sim 10 \mu \mathrm{M}$ (Fig. $4 \mathrm{~B}$ ). These concentrations are consistent with those used to induce $C Y P 3 A$ gene expression in either rodent and/or human primary hepatocytes $(15,16,19-22)$. Although blood concentrations of dexamethasone, lovastatin, and clotrimazole do not normally reach micromolar concentrations in patients, the fact that these drugs are administered in oral doses that can range from several milligrams for dexamethasone to $60 \mathrm{mg} / \mathrm{kg} /$ day for clotrimazole (23-25) suggests that these drugs are likely to reach the concentrations required to activate hPXR during first-pass metabolism in the intestine and liver.

We also tested several naturally occurring C21 steroids on hPXR that were previously shown to activate mPXR1 (7). Pregnenolone, progesterone, and 5 $\beta$-pregnane-3,20-dione all activated hPXR roughly fourfold. The 17-hydroxy derivatives of pregnenolone and progesterone were weak activators of hPXR (Fig. $4 A$ ). These natural steroids all activated hPXR in transient transfection assays with $\mathrm{EC}_{50}$ values $>10 \mu \mathrm{M}$, suggesting that they are unlikely to be natural hPXR ligands. However, related pregnanes or pregnane metabolites may serve as natural hPXR ligands.

Analyses of the effects of chemical inducers of $C Y P 3 A$ gene expression in primary hepatocytes obtained from either rodents or humans have revealed significant interspecies differences $(5,15)$. For example, rifampicin is an efficacious inducer of $C Y P 3 A 4$ gene expression in human hepatocytes but has little or no effect on $C Y P 3 A 1$ levels in rat hepatocytes. In contrast, PCN has marked effects on $C Y P 3 A$ levels in rat hepatocytes but only modest effects in human hepatocytes. To examine whether differences in PXR activation profiles might account for these interspecies variations, we tested the same panel of compounds on mPXR1. As shown in Fig. $4 A$, there were marked differences in the response profiles of the mouse and human homologs of PXR. Whereas rifampicin was an efficacious activator of hPXR, it was only a weak activator of mPXR1 (Fig. 4 A). Clotrimazole, lovastatin, and phenobarbital were also more efficacious activators of hPXR than mPXR1. In contrast, PCN only activated hPXR approximately threefold but activated mPXR1 roughly ninefold (Fig. $4 A$ ). Taken together, these data indicate that much of the interspecies variability in $C Y P 3 A$ regulation may be due to differences in PXR activation profiles.

We also profiled the panel of chemicals that induce $C Y P 3 A$ expression on the human glucocorticoid receptor (GR). As shown in Fig. $4 A$, only dexamethasone and dexamethasonet-butylacetate were efficacious activators of the GR. None of the other compounds activated the GR $>1.5$-fold (Fig. $4 A$ ). We note that in contrast to a recent report (26), we failed to see activation of the GR by rifampicin. Since this previous work was performed in HepG2 cells, it may be that rifampicin is differentially metabolized in various cell lines. As expected, pregnenolone, progesterone, and their 17-hydroxy derivatives did not have an effect on GR activity (Fig. $4 A$ ). Thus, the broad activation profile that we observed for the human and mouse homologs of PXR with inducers of $C Y P 3 A$ gene expression is not a general property of other steroid hormone receptors.

The hPXR activators we identified in transfection assays were not sufficiently potent for use as radioligands in standard binding assays to determine whether they interacted directly with this orphan receptor. Thus, we turned to a sensitive coac- 

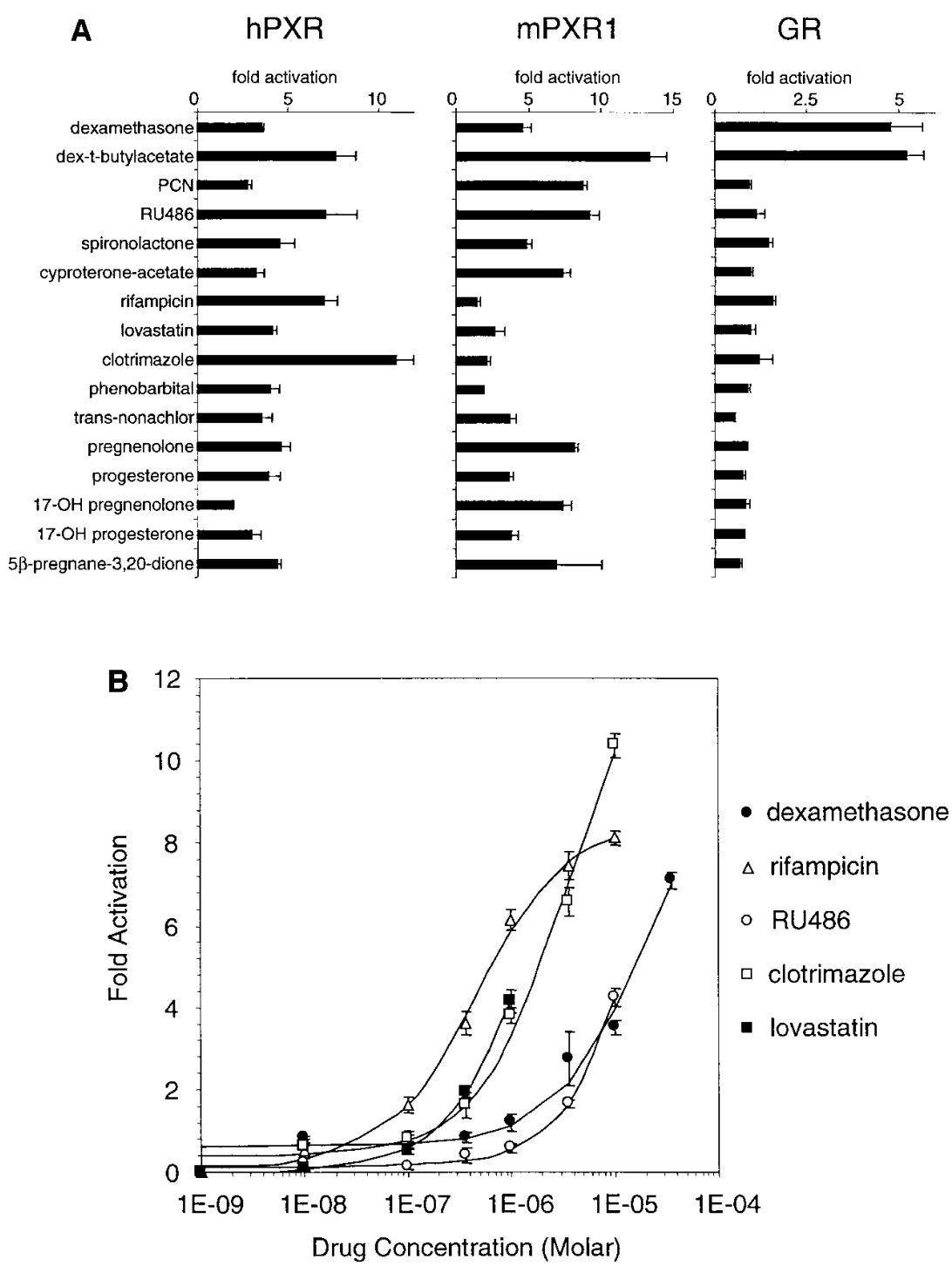

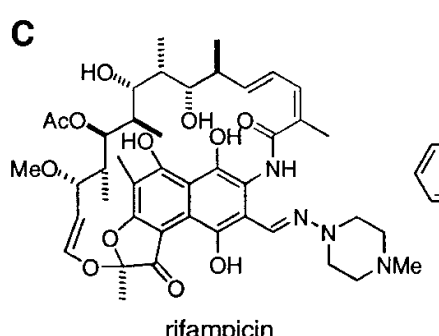

rifampicin

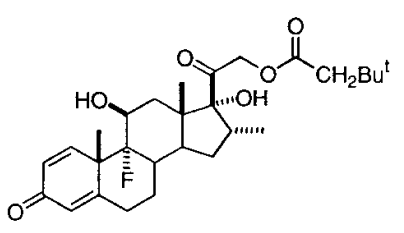

dexamethasone-t-butylacetate

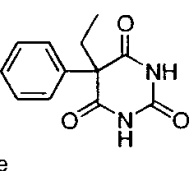

phenobarbital

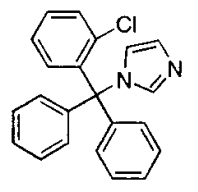

clotrimazole

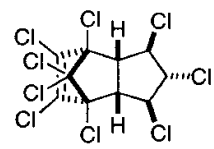

trans-nonachlor<smiles>CC#C[C@]1(O)CCC2C3CCC4=CC(=O)CCC4=C3C(c3ccc(N(C)C)cc3)CC21C</smiles>

RU486

Figure 4. hPXR is activated by structurally distinct inducers of $C Y P 3 A 4$ gene expression. ( $A$ ) CV-1 cells were transfected with the pSG5-hPXR $\Delta$ ATG or pSG5-mPXR1 expression plasmids and the (ER6) ${ }_{3}$-tk-CAT reporter (left and middle, respectively) or the RS-hGR expression plasmid and a reporter containing two copies of a consensus glucocorticoid response element upstream of tk-CAT (right). Cells were treated with $1 \mu \mathrm{M}$ lovastatin, $100 \mu \mathrm{M}$ phenobarbital, or $10 \mu \mathrm{M}$ of the other compounds. Cell extracts were subsequently assayed for CAT activity. Data represent the mean of assays performed in triplicate \pm SE. $(B) \mathrm{CV}-1$ cells were transfected with the pSG5-hPXR $\Delta$ ATG expression plasmid and the (ER6) $)_{3}$-tk-CAT reporter and dose response analysis was performed with dexamethasone, rifampicin, RU486, clotrimazole, and lovastatin. Cell extracts were subsequently assayed for CAT activity. Data represent the mean of assays performed in triplicate \pm SE. Lovastatin was toxic to the cells at concentrations $>1 \mu \mathrm{M}$. $\mathrm{EC}_{50}$ values were calculated by fitting a sigmoidal curve to the data. $(C)$ Structures of representative compounds that activate hPXR. tivator-based assay as a biochemical means to determine whether these compounds interacted directly with hPXR (7, 27). This assay is predicated on the finding that ligands induce the interaction of nuclear receptors with accessory proteins termed coactivators (27). We recently demonstrated that several steroidal activators of mPXR1 including dexamethasonet-butylacetate and PCN promote the interaction of the mPXR1 LBD with a 14-kD fragment of the steroid receptor 


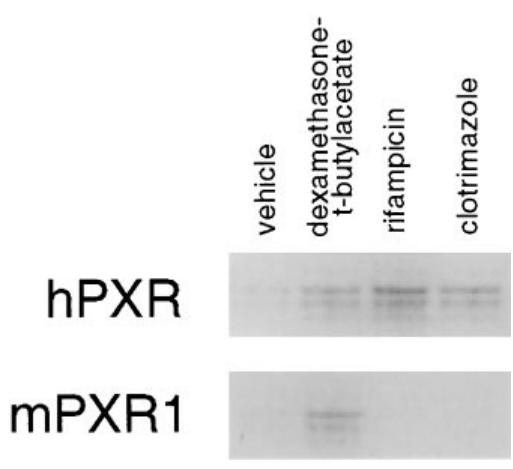

Figure 5. Activators of hPXR promote its interaction with a fragment of the coactivator SRC-1. CARLA was performed with bacterially-expressed GSThPXR or GST-mPXR1 and $\left[{ }^{35} \mathrm{~S}\right] \mathrm{SRC} 1.14$ synthesized in vitro. $\left.{ }^{35} \mathrm{~S}\right] \mathrm{SRC} 1.14$ was mixed with either GST hPXR or GST-mPXR1 in the presence of vehicle alone (1\% DMSO) or $10 \mu \mathrm{M}$ of dexamethasone-t-butylacetate, rifampicin, or clotrimazole. $\left[{ }^{35} \mathrm{~S}\right] \mathrm{SRC} 1.14$ complexed with GSThPXR (top) or GST-mPXR1 (bottom) was precipitated with glutathione-sepharose beads.

coactivator 1 (SRC1.14) (7). To examine whether the structurally diverse compounds that activate hPXR do so by acting as ligands, we selected three of the more potent activators representing different chemical classes, dexamethasone-t-butylacetate, rifampicin, and clotrimazole, for testing in the coactivator-receptor ligand assay (CARLA; 27). The LBDs of hPXR and mPXR1 were expressed in Escherichia coli as fusion proteins with glutathione-S-transferase (GST), and SRC1.14 was synthesized in vitro in the presence of $\left[{ }^{35}\right.$ S $]$ methionine and $\left[{ }^{35}\right.$ S $]$ cysteine. As shown in Fig. 5, dexamethasone-t-butylacetate, rifampicin, and clotrimazole each promoted the interaction of ${ }^{35}$ S]SRC1.14 with GST-hPXR at a concentration of 10 $\mu \mathrm{M}$. In agreement with the results of the transfection studies, dexamethasone-t-butylacetate induced an interaction between GST-mPXR1 and $\left[{ }^{35} \mathrm{~S}\right] \mathrm{SRC} 1.14$ whereas rifampicin and clotrimazole did not (Fig. 5). Taken together, these data indicate that structurally diverse compounds can serve as hPXR ligands and that the human and mouse homologs of PXR differ significantly in terms of their ligand binding properties.

\section{Discussion}

Over the past decade, expression of the CYP3A4 gene has been found to be induced by an array of structurally diverse compounds $(2,3)$. Given the importance of CYP3A4 in the metabolism of a variety of drugs, an understanding of this phenomenon is crucial in minimizing the potential for interactions between drugs. However, the molecular basis for the induction of the CYP3A4 gene by these compounds had remained an enigma. Moreover, the structural diversity of the compounds that induce CYP3A4 transcription and the fact that some of these compounds were known to interact with classic steroid hormone receptors suggested that multiple signal transduction pathways might be involved. We now provide evidence that many of the compounds that exert effects on CYP3A4 gene expression do so through the activation of a single orphan nuclear receptor, hPXR. Our results not only suggest a molecular mechanism underlying the effects of these disparate compounds on CYP3A4 induction but also suggest that hPXR transactivation assays could be used to predict the effects of compounds on $C Y P 3 A 4$ induction.
Given that hPXR and mPXR1 share $\sim 80 \%$ amino acid identity in their LBDs and have activation profiles that differ with respect to certain compounds, the question arises as to whether these two clones are in fact bona fide homologs. We believe that hPXR and mPXR1 are homologs for several reasons. First, the two orphan receptors are very closely related in their DBDs, sharing 96\% amino acid identity. Consistent with this fact, hPXR and mPXR1 display virtually identical DNA binding properties (Fig. $3 C$ and data not shown). Both hPXR and mPXR1 bind efficiently as heterodimers with RXR to the DR3- and ER6-type PXREs that are crucial in the regulation of the CYP3A1 and CYP3A4 genes, respectively. Second, hPXR and mPXR1 display similar tissue expression patterns. Both receptors are predominantly expressed in the liver and tissues of the gastrointestinal tract. These are the same tissues in which the CYP3A genes are most abundantly expressed. And third, hPXR and mPXR1 are activated by many of the same compounds, including naturally occurring pregnanes such as pregnenolone and progesterone, suggesting that they may share a common natural ligand. While these data together are suggestive, proof that these orphan receptors are homologs awaits a more thorough characterization of the human and mouse genomes.

Previous work had demonstrated marked interspecies differences in the induction of $C Y P 3 A$ genes in response to various compounds in primary hepatocytes $(5,15)$. Transfection studies in which CYP3A4 promoter plasmids were introduced into primary hepatocytes from different species indicated that these differences were a consequence of host cell factors rather than the promoter regions of the $C Y P 3 A$ genes (5). Our data with hPXR now provide a molecular explanation for these species-specific effects. Although hPXR and mPXR1 are activated by many of the same compounds, there are important differences in their activation profiles. Notably, rifampicin had virtually no activity on mPXR1 but was a very efficient activator of hPXR. Conversely, PCN was only a weak activator of hPXR but an efficacious activator of mPXR1. These differences in PXR activation profiles correlate well with $C Y P 3 A$ induction data obtained from experiments performed with rat and human primary hepatocytes $(5,15)$. Thus, much of the species specificity in the induction of $C Y P 3 A$ by xenobiotics is likely to be a consequence of differences at the level of PXR activation.

Because of the importance of CYP3A4 in the metabolism of drugs, the development of in vitro assays for rapidly and accurately predicting the effects of compounds on $C Y P 3 A 4$ gene expression in humans has been a long-standing goal in the fields of pharmacology and toxicology. To date, CYP $3 A 4$ induction assays have been almost exclusively dependent upon the use of human liver tissue and primary hepatocytes. Thus, the use of these assays was severely limited by the availability and quality of donor tissue. We now have demonstrated that a number of compounds that are known to regulate CYP3A4 levels function as activators of hPXR in transfection studies. While additional studies are required to strengthen this correlation, the use of hPXR transactivation assays appears to provide a rapid and relatively inexpensive means for predicting whether compounds will induce CYP3A4 levels in vivo. Such assays will be useful for studying the basis for interactions between drugs that are currently in use as well as in minimizing the potential for drug interactions as new medicines are developed. 


\section{References}

1. Nebert, D.W., and F.J. Gonzalez. 1987. P450 genes: structure, evolution, and regulation. Ann. Rev. Biochem. 56:945-993.

2. Maurel, P. 1996. The CYP3A family. In Cytochromes P450: Metabolic and Toxicological Aspects. C. Ioannides, editor. CRC Press, Inc., Boca Raton, FL. 241-270.

3. Guzelian, P.S. 1988. Regulation of the glucocorticoid-inducible cytochromes P450. In Microsomes and Drug Oxidations. J.O. Miners, D.J. Birkett, R. Drew, and M. McManus, editors. Taylor and Francis, London. 148-155.

4. Hashimoto, H., K. Toide, R. Kitamura, M. Fujita, S. Tagawa, S. Itoh, and T. Kamataki. 1993. Gene structure of CYP3A4, an adult-specific form of cytochrome P450 in human livers, and its transcriptional control. Eur. J. Biochem. 218:585-595.

5. Barwick, J.L., L.C. Quattrochi, A.S. Mills, C. Potenza, R.H. Tukey, and P.S. Guzelian. 1996. Trans-species gene transfer for analysis of glucocorticoidinducible transcriptional activation of transiently expressed human CYP3A4 and rabbit CYP3A6 in primary cultures of adult rat and rabbit hepatocytes. Mol. Pharmacol. 50:10-16.

6. Luckow, B., and G. Schütz. 1987. CAT constructions with multiple unique restriction sites for the functional analysis of eukaryotic promoters and regulatory elements. Nucleic Acids Res. 15:5490.

7. Kliewer, S.A., J.T. Moore, L. Wade, J.L. Staudinger, M.A. Watson, S.A. Jones, D.D. McKee, B.B. Oliver, T.M. Willson, R.H. Zetterstrom, et al. 1998. An orphan nuclear receptor activated by pregnanes defines a novel steroid signaling pathway. Cell. 92:73-82.

8. Lehmann, J.M., L.B. Moore, T.A. Smith-Oliver, W.O. Wilkison, T.M. Willson, and S.A. Kliewer. 1995. An antidiabetic thiazolidinedione is a high affinity ligand for peroxisome proliferator-activated receptor $\gamma(\operatorname{PPAR} \gamma)$. J. Biol. Chem. 270:12953-12956.

9. Smith, D.P., C.S. Mason, E.A. Jones, and R.W. Old. 1994. A novel nuclear receptor subfamily member in Xenopus that associates with RXR and shares extensive sequence similarity to the mammalian vitamin D3 receptor. Nucleic Acids Res. 22:66-71.

10. Kozak, M. 1991. Structural features in eukaryotic mRNAs that modulate the initiation of translation. J. Biol. Chem. 266:19867-19870.

11. Nagpal, S., A. Zelent, and P. Chambon. 1992. RAR- $\beta 4$, a retinoic acid receptor isoform generated from RAR- $\beta 2$ by alternative splicing and usage of a CUG initiator codon. Proc. Natl. Acad. Sci. USA. 89:2718-2722.

12. Quattrochi, L.C., A.S. Mills, J.L. Barwick, C.B. Yockey, and P.S. Guzelian. 1995. A novel cis-acting element in a liver cytochrome P450 3A gene confers synergistic induction by glucocorticoids plus antiglucocorticoids. J. Biol. Chem. 270:28917-28923.

13. Huss, J.M., S.I. Wang, A. Astrom, P. McQuiddy, and C.B. Kasper. 1996. Dexamethasone responsiveness of a major glucocorticoid-inducible CYP3A gene is mediated by elements unrelated to a glucocorticoid receptor binding motif. J. Biol. Chem. 93:4666-4670.
14. Molawa, D.T., E.G. Schuetz, S.A. Wrighton, P.B. Watkins, P. Kremers, G. Mendez-Picon, G.A. Parker, and P.S. Guzelian. 1986. Complete cDNA sequence of a cytochrome P-450 inducible by glucocorticoids in human liver. Proc. Natl. Acad. Sci. USA. 83:5311-5315.

15. Kocarek, T.A., E.G. Schuetz, S.C. Strom, R.A. Fisher, and P.S. Guzelian. 1995. Comparative analysis of cytochrome P4503A induction in primary cultures of rat, rabbit, and human hepatocyes. Drug Metab. Dispos. 23:415-421.

16. Schuetz, E.G., and P.S. Guzelian. 1984. Induction of cytochrome P-450 by glucocorticoids in rat liver. J. Biol. Chem. 259:2007-2012.

17. Heuman, D.M., E.J. Gallagher, J.L. Barwick, N.A. Elshourbagy, and P.S. Guzelian. 1982. Immunochemical evidence for induction of a common form of hepatic cytochrome P-450 in rats treated with pregnenolone-16a-carbonitrile or other steroidal or non-steroidal agents. Mol. Pharmacol. 21:753-760.

18. Schulte-Hermann, R., H. Ochs, W. Bursch, and W. Parzefall. 1988. Quantitative structure-activity studies on effects of sixteen different steroids on growth and monooxygenases of rat liver. Cancer Res. 48:2462-2468.

19. Wrighton, S.A., P. Maurel, E.G. Schuetz, P.B. Watkins, B. Young, and P.S. Guzelian. 1985. Identification of the cytochrome P-450 induced by macrolide antibiotics in rat liver as glucocorticoid responsive cytochrome P-450p. Biochemistry. 24:2171-2178.

20. Hostetler, K.A., S.A. Wrighton, D.T. Molawa, P.E. Thomas, W. Levin, and P.S. Guzelian. 1989. Coinduction of multiple hepatic cytochrome P-450 proteins and their mRNAs in rats treated with imidazole antimycotic agents. Mol. Pharmacol. 35:279-285.

21. Kocarek, T.A., E.G. Schuetz, and P.S. Guzelian. 1993. Regulation of phenobarbital-inducible cytochrome P450 2B1/2 mRNA by lovastatin and oxysterols in primary cultures of adult rat hepatocytes. Toxicol. Appl. Pharmacol. 120:298-307.

22. Schuetz, E.G., J.D. Schuetz, S.C. Strom, M.T. Thompson, R.A. Fisher, D.T. Molawa, D. Li, and P.S. Guzelian. 1993. Regulation of human liver cytochromes $\mathrm{P}-450$ in family $3 \mathrm{~A}$ in primary and continous culture of human hepatocytes. Hepatology. 18:1254-1262.

23. Physicians Desk Reference. 1992. Medical Economics Data, Montvale, NJ.

24. Sawyer, P.R., R.N. Brogden, R.M. Pinder, T.M. Speight, and G.S Avery. 1975. Clotrimazole: a review of its antifungal activity and therapeutic efficacy. Drugs. 9:424-447.

25. Brugnara, C., B. Gee, C.C. Armsby, S. Kurth, M. Sakamoto, N. Rifai, S.L. Alper, and O.S. Platt. 1996. Therapy with oral clotrimazole induces inhibition of the gardos channel and reduction of erythrocyte dehydration in patients with sickle cell disease. J. Clin. Invest. 97:1227-1234.

26. Calleja, C., J.M. Pascussi, J.C. Mani, P. Maurel, and M.J. Vilarem. 1998. The antibiotic rifampicin is a nonsteroidal ligand and activator of the human glucocorticoid receptor. Nat. Med. 4:92-96.

27. Krey, G., O. Braissant, F. L'Horset, E. Kalkhoven, M. Perroud, M.G. Parker, and W. Wahli. 1997. Fatty acids, eicosanoids, and hypolipidemic agents identified as ligands of peroxisome proliferator-activated receptors by coactivator-dependent receptor ligand assay. Mol. Endocrinol. 11:779-791. 